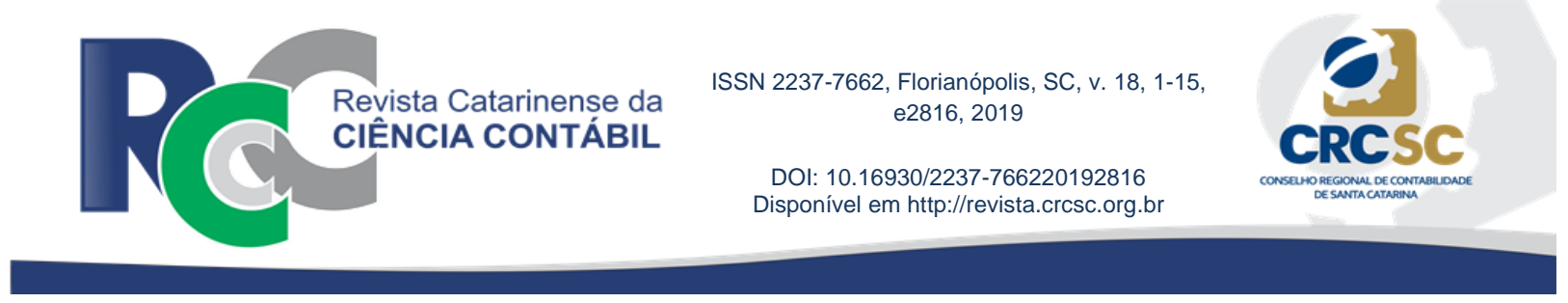

\title{
EVIDÊNCIAS DE INFORMAÇÕES OFF BALANCE NO BALANÇO GERAL DA UNIÃO
}

\author{
EVIDENCE OF OFF-BALANCE INFORMATION IN THE CONSOLIDATED \\ FINANCIAL STATEMENT OF THE BRAZILIAN FEDERAL GOVERNMENT
}

\author{
DIANA VAZ DE LIMA \\ Universidade de Brasília. Endereço: Campus Universitário Darcy Ribeiro, \\ s/n, Prédio da FACE - Salas B1-02, Asa Norte | 70.910-900 | Brasília/DF | \\ Brasil. \\ (1) http://orcid.org/0000-0002-4477-445X \\ diana_lima@unb.br

\section{DIEGO RODRIGUES BOENTE} \\ Fucape Business School. Endereço: SCS Quadra 07 Bloco A no 100, Sala \\ 1305 - Edifício Torre do Pátio Brasil, Asa Sul | 70.307-901 | Brasília/DF | \\ Brasil. \\ Dhttp://orcid.org/0000-0002-2970-7427 \\ diegoboente@gmail.com
}

\section{GABRIEL LOPES BARROS}

Universidade de Brasília. Endereço: Campus Universitário Darcy Ribeiro, s/n, Prédio da FACE - Salas B1-02, Asa Norte | 70.910-900 | Brasília/DF | Brasil.

(D) http://orcid.org/0000-0001-8524-5303

bieltimao2008@gmail.com

\section{RESUMO}

Este estudo tem como objetivo identificar evidências de informações off balance no Balanço Geral da União (BGU). Para alcançar tal propósito, foram delimitados os conhecimentos acerca das demonstrações contábeis como núcleo da informação contábil, percorridos os passos observados para elaboração e apreciação do BGU pelas instituições do Governo Federal brasileiro e caracterizado o que é informação off balance. Do ponto de vista metodológico, foi aplicada a técnica da análise documental, tendo como base o Capítulo 5 do Relatório e o Parecer Prévio sobre as Contas do Governo da República, elaborado pelo Tribunal de Contas da União (TCU), relativo ao período de 2013 a 2015, dividindo o roteiro didático em três etapas: leitura flutuante, na etapa da pré-análise; desmembramento do texto por ano e por grupos de contas, na etapa da exploração do material; e apresentação de resultados, com destaque para as informações fornecidas pelas análises, na etapa final. Também foram utilizados os relatórios de Prestação de Contas do Presidente da República, elaborados pela Controladoria-Geral da União (CGU), relativos ao período de 2013 a 2015, para observar os impactos dessas informações no BGU. Os achados do estudo mostram que as informações off balance resultaram em perdas da 
confiabilidade e fidedignidade das informações analisadas, implicando o montante não registrado de quase R \$ 1,9 trilhão em 2013, R \$ 37,5 bilhões em 2014 e R \$ 23,88 bilhões em 2015.

Palavras-chave: BGU. Evidenciação. Informação Contábil. Setor Público.

\begin{abstract}
This study aimed at identifying of off-balance information in the Consolidated Financial Statement of the Brazilian Federal Government (GBS). In order to achieve this purpose, we delimited the knowledge about the financial statements as the core of the accounting information, following the steps taken to elaborate and evaluate the Brazilian Federal Government institutions GBS and characterized what is information off-balance. From a methodological point of view, the document analysis technique was applied, based on Chapter 5 of the Report and the Prior Opinion on the General Government Accounts of the Republic, prepared by the Federal Court of Accounts (TCU), for the period between 2013 to 2015, dividing the didactic script into three stages: superficial reading, in the pre-analysis stage; splitting of the text by year and by groups of accounts, in the material exploitation stage; and presentation of results, highlighting the information provided by the analyzes, in the final stage. The Accounts of the President of the Republic reports, prepared by the Comptroller General of the Union (CGU), were also used for the period from 2013 to 2015 to observe the impacts of this information on the GBS. The findings of the study show that the off-balance information resulted in reliability and trustworthiness losses in the information analyzed, implying an unregistered amount of almost $R \$ 1.9$ trillion in 2013, $R \$ 37.5$ billion in 2014 and $R \$ 23,88$ billion in 2015.
\end{abstract}

Keywords: GBS. Disclosure. Accounting Information. Public sector.

\title{
1 INTRODUÇÃO
}

Segundo Silva, Gonçalves, Tavares, e Lima, (2010, p. 18), em situações ideais, o contador deveria tomar decisões tendo como base seu conhecimento da ciência, sem deixar-se influenciar por questões do ambiente. Ao analisar a influência do incentivo ao conservadorismo nas escolhas contábeis relacionadas ao reconhecimento da provisão de contingências passivas, os autores verificaram que a presença de um chamariz pode afetar as decisões contábeis e, além disso, essa influência pode variar conforme o perfil do indivíduo.

A Norma Brasileira de Contabilidade do Setor Público (NBC TSP) - na norma da Estrutura Conceitual aplicada ao Setor Público, editada pelo Conselho Federal de Contabilidade (CFC) - apresenta que a omissão de algumas informações pode fazer com que a representação dos atos e fatos contábeis seja falsa ou enganosa, trazendo com isso a perda de utilidade da informação para o usuário (item 3.12). De acordo com a norma, a seleção e apresentação das informações financeiras e não financeiras não devem ser feitas com a intenção de atingir um resultado particular predeterminado, pois pode influenciar a avaliação dos usuários acerca da prestação de contas e responsabilização por parte da entidade (item 3.13) (CFC, 2016).

Na visão de Cruvinel e Lima (2011, p. 77), o objetivo da Contabilidade Pública é a representação fiel do patrimônio das entidades, sendo assim, a informação contábil deve mostrar a situação real do ente público e não o interesse de particulares (Amaral \& Lima, 2013, p. 175).

Ao comentar sobre a necessidade de mais pesquisas sobre manipulação do Balanço Patrimonial (Balance Sheet Management), Stolowy e Breton (2004, p. 29), como citado em Paulo (2007, p. 65), colocam como principais itens de pesquisa as informações que estão fora dessa demonstração (off-balance sheet). Lewis (2013) alerta que cada vez mais tem havido o desenvolvimento de práticas financiadas fora do balanço, impedindo de reconhecer a integralidade dos ativos e passivos. 
No Brasil, a qualidade das informações contábeis divulgadas no âmbito do Governo Federal somente passou a ser discutida recentemente, com as "pedaladas fiscais", cuja prática, segundo Villaverde e Fernandes (2015), foi entendida como crime de responsabilidade fiscal, sendo fato importante para o impeachment da ex-presidente Dilma Rousseff.

Para Schroeder (2001, p. 544), como citado em Xavier, Paulo e Da Silva (2014, p. 2), as demonstrações contábeis fazem parte de um sistema amplo de divulgação, além do mais, "as informações mais relevantes devem sempre ser apresentadas nas demonstrações contábeis". Segundo Reis, Lima e Wilbert (2015, p. 12), as notas explicativas são parte integrante das demonstrações contábeis, porém não substitui seu conteúdo, tanto que a Lei de Responsabilidade Fiscal (LRF), em busca da transparência dos entes públicos, vem exigindo mais publicidade das demonstrações contábeis emitidas por essas entidades (Xavier et al, 2014, p. 2).

Considerando que a inadequada evidenciação do patrimônio público e a ausência de procedimentos contábeis suportados por adequados conceitos e princípios revelam a necessidade de se desenvolverem diretrizes estratégicas para o aperfeiçoamento da Contabilidade aplicada ao Setor Público (CFC, 2007), e que a informação contábil deve permitir a avaliação dos aspectos de economicidade, eficiência e eficácia na aplicação dos recursos para prestação de serviços públicos (CFC, 2016), este estudo tem como questão norteadora: há evidências de informações off balance no Balanço Geral da União (BGU)?

Assim, o objetivo do trabalho foi identificar evidências de informações off balance no BGU, por meio da técnica da análise documental, tendo como base de análise o Capítulo 5 do Relatório e o Parecer Prévio sobre as Contas do Governo da República, elaborado pelo Tribunal de Contas da União, relativo ao período de 2013 a 2015, e os relatórios de Prestação de Contas do presidente da República, elaborados pela Controladoria-Geral da União (CGU), relativos ao período de 2013 a 2015.

Além da introdução, este estudo apresenta mais quatro seções. Na Seção 2, é apresentado o referencial teórico e normativo sobre o tema, trazendo as demonstrações contábeis como núcleo da informação contábil, os passos para elaboração e apreciação do BGU, e o referencial teórico sobre as informações off balance. A metodologia utilizada no estudo é demonstrada na Seção 3. Na Seção 4, são apresentados os resultados obtidos a partir da análise realizada, mostrando as evidências de informações off balance identificadas e seus impactos no BGU. As considerações finais do estudo e a sugestão para futuras pesquisas são apresentadas na Seção 5, seguidas das referências utilizadas.

\section{FUNDAMENTAÇÃO TEÓRICA}

\subsection{As Demonstrações Contábeis como Núcleo da Informação Contábil}

Segundo o disposto na Estrutura Conceitual aplicada ao Setor Público brasileiro (CFC, 2016), os Governos devem prestar contas àqueles que proveem seus recursos, bem como àqueles que dependam deles para que os serviços sejam prestados durante determinado exercício ou em longo prazo (item 2.8).

Augustinho e Oliveira (2014, p. 55) entendem que as demonstrações contábeis são os principais e mais relevantes documentos de evidenciação da prestação de contas dos agentes públicos. No papel de núcleo da informação contábil, as demonstrações contábeis retratam os efeitos financeiros e não financeiros das transações e outros eventos ao agrupá-los em classes amplas que compartilham características econômicas comuns, denominadas de elementos das demonstrações contábeis (CFC, 2016).

Segundo a International Federation of Accountants (IFAC), os elementos correspondem às estruturas básicas a partir das quais as demonstrações contábeis são elaboradas: Ativo, Passivo, Patrimônio Líquido, Receita e Despesa (IFAC, 2010, item 1.7). Em algumas circunstâncias, para assegurar que as demonstrações contábeis forneçam informação útil para 
uma avaliação significativa do desempenho e da situação patrimonial da entidade, o reconhecimento de fenômenos econômicos não capturados pelos elementos definidos anteriormente podem ser necessários (item 5.4) (CFC, 2016).

Para a NBC T SP Estrutura Conceitual, o reconhecimento de um elemento patrimonial é o processo de incorporar e incluir um item expresso em valores a serem demonstrados no corpo da demonstração contábil apropriada que satisfaça a definição de elemento, e possa ser mensurado de maneira que se observe as características qualitativas, levando em consideração as restrições sobre a informação incluída nos relatórios contábeis de propósito geral da entidade do setor público (RCPG) (itens 6.1 e 6.2) (CFC, 2016).

Outro ponto estabelecido nessa estrutura conceitual é que os responsáveis pela elaboração dos RCPG devem revisar e avaliar toda a evidência disponível ao determinarem se o elemento existe e se deve ser reconhecido, se aquele elemento continua qualificado para o reconhecimento, ou se houve mudança em elemento existente (item 6.6) (CFC,2016).

\subsection{Elaboração do Balanço Geral da União}

No âmbito do Governo Federal brasileiro, conjuntamente com as informações orçamentárias e financeiras, as informações contábeis são congregadas nas Demonstrações Contábeis Consolidadas da União - comumente conhecidas como Balanço Geral da União (BGU) - englobando, entre outros, as contas de todos os órgãos e entidades da Administração Pública Federal, acompanhado do Relatório das Atividades desenvolvidas no período (Macrofunção SIAFI 010400).

De acordo com o Tribunal de Contas da União (TCU) (2015, p. 13), a competência para elaborar e consolidar o BGU é da Secretaria do Tesouro Nacional (STN) do Ministério da Fazenda, conforme art. 18, inciso VI, da Lei 10.180 de 6 de fevereiro de 2001, c/c o art. $7^{\circ}$, inciso VI, do Decreto 6.976 de 7 de outubro de 2009. No entendimento de Passos (2012, p. 125), para que sejam divulgadas as informações no BGU a STN utiliza o Sistema Integrado de Administração Financeira (SIAFI), que contabiliza os atos e fatos praticados pelos gestores públicos ao longo do exercício financeiro no âmbito do Governo Federal brasileiro.

Após o envio das informações ao Siafi, os contabilistas das unidades jurisdicionadas devem emitir uma declaração confirmando a adequação das demonstrações contábeis com as normas brasileiras de contabilidade (Macrofunção SIAFI 020318, item 8.1.1). Caso haja alguma ressalva, essa declaração deve fazer parte das notas explicativas ao BGU, cabendo à STN avaliar eventuais inconsistências, irregularidades ou ressalvas (Macrofunção SIAFI 020318, item 8.1.2)

A elaboração do BGU é então concretizada com a consolidação de todas essas informações, sendo que as entidades que utilizam o Siafi na modalidade total terão os dados integrados automaticamente. Para os órgãos que não atenderem esses critérios, procedimentos adicionais serão exigidos, como o encaminhamento de balancetes e demonstrativos da execução orçamentária às respectivas Setoriais de Contabilidade, que realizarão a integralização dos saldos contábeis dentro do mês aberto (Macrofunção SIAFI 020311, item 2.2 e 4).

O BGU é composto pelas seguintes demonstrações contábeis:

a) Balanço Patrimonial (BP): demonstração contábil que evidencia, qualitativa e quantitativamente, a situação patrimonial da entidade pública por meio de contas representativas do patrimônio público, bem como os atos potenciais, que são registrados em contas de compensação;

b) Balanço Orçamentário (BO): demonstração contábil que evidencia as receitas e despesas orçamentárias previstas, em confronto com as realizadas;

c) Balanço Financeiro (BF): demonstração contábil que evidencia as receitas e despesas orçamentárias, bem como os ingressos e dispêndios extraorçamentários, conjugados com os saldos de caixa do exercício anterior e os que se transferem para o início do exercício seguinte; 
d) Demonstração das Variações Patrimoniais (DVP): demonstração contábil que evidencia as alterações verificadas no patrimônio, resultantes ou independentes da execução orçamentária, indicando o resultado patrimonial do exercício;

e) Demonstração das Mutações do Patrimônio Líquido (DMPL): demonstração contábil que mostra a evolução do patrimônio líquido da entidade, exigida apenas para as estatais dependentes, desde que constituídas sob a forma de sociedade anônima;

f) Demonstração dos Fluxos de Caixa (DFC): demonstração contábil que evidencia os fluxos de entradas e saídas de caixa.

A Macrofunção Siafi 010400 - Glossário estabelece que o BGU deve ser encaminhado ao Congresso Nacional brasileiro anualmente com os dados do exercício anterior, dentro de sessenta dias após a abertura da sessão legislativa (inciso XXIV, art. 84, da Constituição Federal). De acordo com o inciso IX, art. 49, da Constituição da República Federativa do Brasil (1988), o Congresso Nacional é o responsável por julgar as contas prestadas pelo presidente da República, das quais o BGU é parte integrante (inciso I, art. 6, da Portaria do CGU n 50.123 de 20 de novembro de 2015).

Passos (2012, p. 126) esclarece que o TCU é o órgão responsável por auditar as prestações de contas do presidente da República e, por consequência, auditar o BGU, enviando recomendações e determinações para a elaboração desse balanço.

Registre-se que para atender ao disposto no art. 71, inciso I, da Constituição Federal de 1988, cabe ao TCU apreciar e emitir parecer prévio conclusivo sobre as contas do presidente da República, subsidiando o órgão de cúpula do Poder Legislativo com elementos técnicos para emitir seu julgamento político.

Segundo o TCU (2015, p. 13), em cumprimento ao seu mandato constitucional e legal, e conforme estabelecem o caput e o $\$ 1^{\circ}$ do art. 228 do Regimento Interno do Tribunal, o parecer prévio é conclusivo no sentido de exprimir:

- Se as contas prestadas pelo presidente da República representam adequadamente a posição financeira, orçamentária, contábil e patrimonial, ao final de cada exercício;

- Se houve observância aos princípios constitucionais e legais que regem a Administração Pública Federal, com destaque para o cumprimento das normas constitucionais, legais e regulamentares na execução dos orçamentos da União e nas demais operações realizadas com recursos públicos federais, em especial quanto ao que estabelece a lei orçamentária anual.

Além disso, o $\S 2^{\circ}$ do mesmo dispositivo regimental estabelece a obrigatoriedade da elaboração de relatório contendo as seguintes informações:

- O cumprimento dos programas previstos na lei orçamentária anual quanto à legitimidade, eficiência e economicidade, bem como o atingimento de metas e a consonância destes com o plano plurianual e com a lei de diretrizes orçamentárias;

- O reflexo da administração financeira e orçamentária federal no desenvolvimento econômico e social do país;

- O cumprimento dos limites e parâmetros estabelecidos pela Lei Complementar 101/2000 - Lei de Responsabilidade Fiscal (LRF).

A prestação de contas enviada ao Congresso Nacional é publicada em formato impresso ou digital no site da CGU, sendo a data de sua publicação a mesma da entrega ao Congresso Nacional (art. 12, da Portaria do CGU no 50.123/15).

Segundo o TCU (2015, p. 14), o parecer prévio emitido pelo Tribunal é um subsídio tanto para o parecer da Comissão Mista de Planos, Orçamentos Públicos e Fiscalização (CMO) - que examina e emite parecer sobre as contas apresentadas anualmente pelo presidente da República (art. 166, § $1^{\circ}$, inciso I, da Constituição Federal de 1988) -, como para o julgamento pelo próprio Congresso Nacional. 
A síntese dos passos observados para elaboração e apreciação do BGU é apresentada na Figura 1, a seguir.

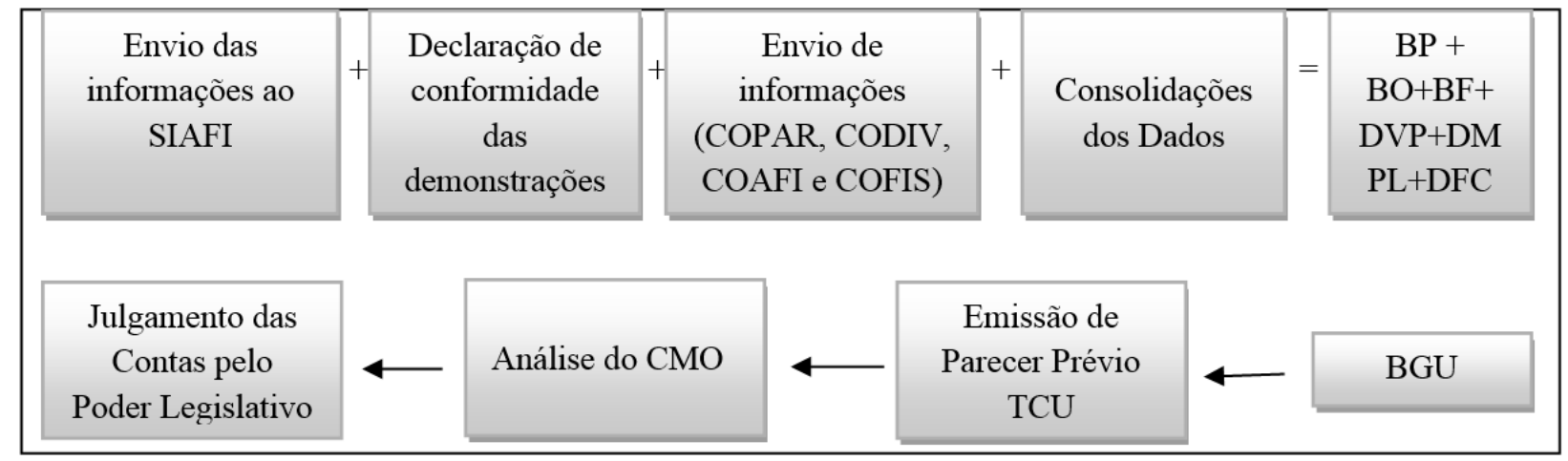

Figura 1. Passos para elaboração e apreciação do BGU

Fonte: elaboração a partir das informações obtidas.

É importante ressaltar que é emitido parecer prévio apenas sobre as contas prestadas pelo presidente da República, pois as contas dos Poderes Legislativo e Judiciário e o Ministério Público não são objeto de pareceres prévios individuais, mas efetivamente julgadas pelo TCU. Contudo, o Relatório sobre as Contas do Governo da República pode contemplar informações sobre os demais Poderes e o Ministério Público, compondo, assim, segundo o TCU (2012, p. 11), um panorama abrangente da Administração Pública Federal.

\subsection{Informações off balance}

Como o próprio nome em inglês sugere, as informações off balance são aquelas que não estão evidenciadas nas demonstrações contábeis. Ao discutir o problema da evidenciação, Lima e Carmo (2014, p. 40) comentam que o Financial Accounting Standards Boards (FASB) apresenta duas dimensões básicas a respeito das informações off balance: a full disclosure versus a Summary Annual Report e o off-balance-sheet. Nessa última, tem-se que as operações contratadas devem ser evidenciadas independentemente de seu registro contábil, por considerarse que sua omissão poderia prejudicar as decisões dos usuários da informação.

Para Iudícibus (1997, p. 115), a presença de informações ocultas ou de forma muito resumida é tão prejudicial ao usuário quanto disponibilizar informação em excesso. Padoveze (2009, p. 52) afirma que a informação contábil "deve ser tratada como qualquer outro produto que esteja disponível para o consumo. Ela deve ser desejada, para ser necessária. Para ser necessária, deve ser útil”.

Tardoque (2011, p. 25) traz alguns atributos para a qualidade da informação contábil, que são: a quantidade de informação prestada, clareza, transparência, precisão, tempestividade, materialidade, relevância e confiabilidade. Dias e Vasconcelos (2015, p. 18) consideram como atributos: a relevância, compreensibilidade, confiabilidade e comparabilidade. Os autores acrescentam que a ausência desses tributos pode prejudicar a decisão do usuário da informação.

Milesi-Ferretti (2004, p. 378) alerta que no âmbito do setor público as leis e as regulamentações podem ser um incentivo para práticas contábeis duvidosas, que acarretam na diminuição da transparência das contas públicas (Benito, Montesinos, \& Bastida, 2008, p. 968).

Outra variável a ser considerada no setor público está no fato de que no Brasil, além do esforço para atender leis, decretos, regulamentos, entre outros, os contabilistas e gestores devem observar as ramificações presentes na contabilidade pública - orçamentária, patrimonial e fiscal, onde o primeiro registra e evidencia a aprovação e execução do orçamento público; o segundo, a evolução do patrimônio público; e o terceiro, os indicadores exigidos pela LRF (MCASP, 2017, p. 23). 
Para Lima (2016), entendendo que essas três ramificações da contabilidade pública devem conviver harmonicamente, é fundamental saber distinguir quando as transações governamentais conseguem atender à cada um dos seus fundamentos, identificando como esses conceitos devem ser observados no "mundo" ao qual pertencem essas transações.

Ao analisar o caso da public-private partnership (PPP), Heald e Georgiou (2011, p. 227) dividiram as formas de evidenciar os ativos em quatro possibilidades: On:On, On:Off, Off:Off e Off:On, conforme a Figura 2.

\begin{tabular}{|c|c|}
\hline $\begin{array}{c}\text { On: Off } \\
\text { No Balanço do Poder Público } \\
\text { Fora do Balanço do Concessionário }\end{array}$ & $\begin{array}{c}\text { On:On } \\
\text { No Balanço do Poder Público } \\
\text { No Balanço do Concessionário }\end{array}$ \\
\hline $\begin{array}{c}\text { Off: Onf } \\
\text { Fora do Balanço do Poder Público } \\
\text { Fora do Balanço do Concessionário }\end{array}$ & $\begin{array}{c}\text { Fora do Balanço do Poder Público } \\
\text { No Balanço do Concessionário }\end{array}$ \\
\hline
\end{tabular}

Figura 2. Formas de evidenciação de ativos

Fonte: Salgado, Wilbert, Lima e Oliveira, (2017, p. 113), adaptado de Heald e Georgiou (2011, p. 227)

No caso das informações Off: On ou Off: Off, os ativos estão fora do balanço do Poder Público. De acordo com Heald e Georgiou (2011, p. 234), existem alguns casos excepcionais nos quais a informação Off: Off é legalizada, porém a existência desses ativos órfãos cria a evidência de que a contabilidade foi distorcida e possivelmente manipulada.

Ressalte-se, contudo, de acordo com Paulo (2007, p. 48), que a manipulação da informação contábil não decorre somente da modificação artificial dos números contábeis, mas, também, da apresentação de certos aspectos econômicos e financeiros.

\section{METODOLOGIA}

Considerando que o objetivo deste artigo é identificar evidências de informações off balance no BGU, esta pesquisa pode ser classificada como descritiva, uma vez que a análise, o registro e a interpretação dos fatos se darão sem a interferência do pesquisador (Barros \& Lehfeld, 2007).

Com relação à forma, trata-se de uma pesquisa documental e bibliográfica. Em termos procedimentais, foi efetuada uma revisão bibliográfica e, posteriormente, aplicada à análise documental, que, segundo Bardin (1979, p. 45) pode ser definida como "uma operação ou conjunto de operações visando representar o conteúdo de um documento sob uma forma diferente do original, a fim de facilitar num estado ulterior, a sua consulta e referenciação". Para Duarte (2008, p. 271), a análise documental "compreende a identificação, a verificação e a apreciação de documentos para determinado fim".

Em termos procedimentais, o primeiro passo foi organizar o material para atingir o objetivo da pesquisa, mediante a análise do conteúdo do Relatório e Parecer Prévio sobre as Contas do Governo da República e a Prestação de Contas do Presidente da República (PCPR), do período de 2013 a 2015, disponíveis nos sites www.tcu.gov.br e www.cgu.gov.br, respectivamente. A partir de uma leitura flutuante do primeiro documento, foi selecionado apenas o capítulo 5, em razão desse capítulo tratar especificamente da auditoria no BGU.

No segundo passo, foram definidas algumas palavras relacionadas com o termo off balance, como "ausência", "falta" ou semelhantes a essas. Depois, essas informações foram retiradas do texto e separadas em anos (2013, 2014 e 2015), que tinham subgrupos: passivo e ativo.

Posteriormente, para tratamento dos dados e interpretação, foram retiradas no PCPR de 2013 e 2014 as informações sobre o ativo financeiro, o ativo não financeiro, o passivo financeiro e o passivo não financeiro do BP, porém no período de 2015, devido à implementação do novo Plano de Contas Aplicado ao Setor Público (PCASP), passaram a ser analisadas as informações do ativo circulante, do ativo não circulante, do passivo circulante e do passivo não circulante. 
$\mathrm{Na}$ sequência, foi realizada uma análise comparativa entre os valores originalmente publicados no BGU e a inclusão das informações off balance a partir dos relatórios analisados. Este estudo tem como limitação o fato de utilizar apenas informações quantificadas no parecer do TCU.

\section{ANÁLISE DOS RESULTADOS}

\subsection{Evidências de informações off balance no BGU em 2013}

Os achados da análise mostram que no ano de 2013 os passivos são a maior parte das informações off balance detectadas pelo TCU, com destaque para o passivo atuarial do Regime Próprio de Previdência Social (RPPS), ultrapassando 1 trilhão de reais. Segundo explicações dos auditores, essa falha no regime de previdência não deveria ocorrer, pois há informações suficientes para o reconhecimento, mensuração e evidenciação desses valores, apesar do Ministério da Previdência Social argumentar que há uma lacuna jurídica e institucional para que esses registros fossem efetuados. Para solução desse problema, foi recomendado pelo TCU que se definisse um órgão competente para efetuar os registros até a criação da Unidade Gestora do regime.

Também foi identificada a ausência de evidência contábil de provisões e passivos contingentes decorrentes de demandas judiciais contra a União, de mais de 700 bilhões de reais. De acordo com os auditores, também havia informações suficientes para sua mensuração, mas caberia aos órgãos setoriais fazer o seu reconhecimento nas demonstrações contábeis.

Na visão do órgão de fiscalização, não houve a necessária classificação desses valores como "remoto", "possível" e "provável": caso tivessem sido adequadamente classificados, provavelmente apenas parte desses valores teria sido reconhecida pelo BGU na ocasião, uma vez que só os valores a serem classificados como "provável” seriam registrados.

Com relação aos ativos, representaram apenas $0,6 \%$ das informações off balance durante o exercício 2013; relativas à omissão do registro da atualização das participações societárias da União, na ordem de 12 bilhões de reais. Segundo os auditores, a defasagem dessa informação deu-se em razão de o Siafi não permitir, na ocasião, que houvesse lançamentos retroativos no mês de janeiro. Registre-se que as empresas publicam trimestralmente essas demonstrações, e que são encerradas apenas no último dia de cada trimestre. Os achados da análise no ano de 2013 estão sintetizados na Tabela 1.

Tabela 1

\section{Informações off balance identificadas em 2013}

\begin{tabular}{l|r}
\hline Passivos & $\mathbf{1 . 8 8 0}$ bi \\
\hline $\begin{array}{l}\text { Ausência de evidenciação contábil do passivo atuarial do Regime Próprio de Previdência Social } \\
\text { (RPPS) dos servidores civis federais (item 5.3.1.1.1); }\end{array}$ & 1,1 trilhão \\
\hline $\begin{array}{l}\text { Ausência de evidenciação contábil de provisões e passivos contingentes decorrentes de } \\
\text { demandas judiciais contra a União (item 5.3.1.1.2); }\end{array}$ & 780 bi \\
\hline Ativos & $\mathbf{1 2}$ bi \\
\hline Falha de divulgação das participações societárias (item 5.3.1.6); & 12 bi \\
\hline
\end{tabular}

A Tabela 2 apresenta o BP do exercício de 2013 publicado originalmente e o balanço adaptado com as informações off balance identificadas nos relatórios analisados. 
Tabela 2

BGU 2013 original e com a inclusão das informações off balance

\begin{tabular}{l|r|l|r}
\hline \multicolumn{2}{l}{ BGU 2013 - Original (em milhares) } & $256.833 .738,57$ \\
\hline Ativo financeiro & $749.316 .970,78$ & Passivo financeiro & $3.142 .132 .411,37$ \\
\hline Ativo não financeiro & $3.832 .118 .235,10$ & Passivo não financeiro & $3.398 .966 .149,94$ \\
\hline Ativo real $^{1}$ & $4.581 .435 .205,88$ & Passivo real & $1.182 .469 .055,94$ \\
\hline \multicolumn{2}{l}{} & Patrimônio Líquido & \\
\hline BGU 2013 - Incluindo as informações off balance (em milhares) & $256.833 .738,57$ \\
\hline Ativo financeiro & $749.316 .970,78$ & Passivo financeiro & $256.833 .738,57$ \\
\hline Ativo financeiro novo & $749.316 .970,78$ & Passivo financeiro novo & $3.142 .132 .411,37$ \\
\hline Ativo não financeiro & $3.832 .118 .235,10$ & Passivo não financeiro & $1.100 .000 .000,00$ \\
\hline Participações societárias & $12.000 .000,00$ & Passivo atuarial do RPPS & $780.000 .000,00$ \\
\hline \multicolumn{2}{|c|}{} & Provisão para passivos judiciais & $5.022 .132 .411,37$ \\
\hline Ativo não financeiro novo & $3.844 .118 .235,10$ & Passivo não financeiro novo & $5.278 .966 .149,94$ \\
\hline Ativo real novo & $4.593 .435 .205,88$ & Passivo real novo & $-685.530 .944,06$ \\
\hline
\end{tabular}

Fonte: resultados obtidos a partir dos dados pesquisados no TCU (2014) e CGU (2014).

Conforme a Tabela 2, as informações não evidenciadas nas demonstrações contábeis do exercício de 2013 impactaram negativamente o BGU na ordem de $158 \%$, saindo de uma situação superavitária de mais de um trilhão de reais para uma situação deficitária de mais de 600 bilhões de reais.

\subsection{Evidências de informações off balance no BGU em 2014}

Em 2014, a análise mostra que apenas houve informações off balance em contas de passivos, como a que levou ao impeachment da ex-presidente Dilma Rousseff, decorrente da omissão de registro relativo aos atrasos nos repasses de recursos aos bancos públicos, referente a programas sociais do governo, sem autorização do Poder Legislativo. Essa situação, na visão dos auditores, deveria ter sido enquadrada como empréstimo, na ordem de 37,5 bilhões de reais, conforme a Tabela 3.

Tabela 3

\section{Informações off balance identificadas em 2014}

\begin{tabular}{l|r}
\hline Passivos & $\mathbf{3 7 , 5}$ bi \\
\hline $\begin{array}{l}\text { Ausência de registro de passivos da União relativos a repasse de recursos de programas sociais. } \\
\text { (item 5.3.1.3) }\end{array}$ & 37,5 bi \\
\hline
\end{tabular}

Fonte: resultados obtidos a partir dos dados pesquisados no TCU (2015).

Ressalta-se que a omissão do registro do empréstimo não foi o único problema no exercício de 2014, pois a obrigação com os programas sociais já deveria estar reconhecida antes de o pagamento ser efetuado junto aos bancos. A Tabela 4 apresenta o BP do exercício de 2014 publicado originalmente e o balanço adaptado com as informações off balance identificadas nos relatórios analisados.

\footnotetext{
${ }^{1}$ Ativo real e Passivo real são termos utilizados no BGU
} 
Tabela 4

BGU 2014 original e com a inclusão das informações off balance

\begin{tabular}{l|r|l|r}
\hline BGU 2014 - Original (em milhares) \\
\hline Ativo financeiro & $700.721 .049,00$ & Passivo financeiro & $269.877 .232,00$ \\
\hline Ativo não financeiro & $4.384 .581 .340,00$ & Passivo não financeiro & $4.697 .329 .247,00$ \\
\hline Ativo real & $5.085 .302 .389,00$ & Passivo real & $4.967 .206 .479,00$ \\
\hline \multicolumn{2}{|r|}{} & Patrimônio Líquido & $118.095 .910,00$ \\
\hline BGU 2014 - Incluindo as informações off balance (em milhares) & $269.877 .232,00$ \\
\hline Ativo financeiro & $700.721 .049,00$ & Passivo financeiro & $37.500 .000,00$ \\
\hline Ativo financeiro novo & $700.721 .049,00$ & Emp. Conc. p/ programa sociais & $307.377 .232,00$ \\
\hline Ativo não financeiro & $4.384 .581 .340,00$ & Passivo financeiro novo & $4.697 .329 .247,00$ \\
\hline Ativo não financeiro novo & $4.384 .581 .340,00$ & Passivo não financeiro & $4.697 .329 .247,00$ \\
\hline Ativo real novo & $5.085 .302 .389,00$ & Passivo não financeiro novo & $5.004 .706 .479,00$ \\
\hline & & Passivo real novo & $80.595 .910,00$ \\
\hline
\end{tabular}

Fonte: resultados obtidos a partir dos dados pesquisados no TCU (2015) e no CGU (2015).

Conforme informações obtidas na Tabela 4, verifica-se que o impacto das informações off balance no Patrimônio Líquido (PL) de 2014 comparativamente ao exercício de 2013 foi menor, porém caso fossem incluídas, as informações off balance identificadas em 2014 impactariam negativamente o PL em mais de $30 \%$.

\subsection{Evidências de informações off balance no BGU em 2015}

Também em 2015 as informações off balance foram classificadas apenas em contas de passivos, relacionadas à ausência do reconhecimento da provisão para passivos judiciais e falta de reconhecimento do Programa de Aceleração do Crescimento (PAC) relativos a passivos decorrentes de etapas de contratos já executadas. Não foram detectados ativos off balance no BGU de 2015, apenas registros superestimando as participações societárias da União junto ao Banco do Brasil. Os achados da análise no ano de 2015 estão sintetizados na Tabela 5.

Tabela 5

\section{Informações off balance identificadas em 2015}

\begin{tabular}{l|r}
\hline Passivo & $\mathbf{2 3 , 8 8} \mathbf{b i}$ \\
\hline Falta de reconhecimento de provisão para passivos judiciais (item 5.3.1.1.1) & 17,74 bi \\
\hline $\begin{array}{l}\text { Falta de reconhecimento do PAC relativos a passivos decorrentes de etapas já executadas de } \\
\text { contratos (item 5.3.3) }\end{array}$ & 6,14 bi \\
\hline Fonte: rutto
\end{tabular}

Fonte: resultados obtidos a partir dos dados pesquisados no TCU (2016).

De acordo com os auditores, em 2015 ainda não havia sido dado o devido tratamento contábil para a constituição de provisões para passivos judiciais por parte da Procuradoria-Geral da Fazenda Nacional (PGFN), mesmo tendo sido definido pela Advocacia Geral da União (AGU) as informações relacionadas às demandas judiciais classificadas como "provável", resultando em 17,74 bilhões de valores omitidos.

A segunda parte das informações off balance do passivo em 2015 foi decorrente das etapas já executadas de contratos do PAC, resultado de um grupo de trabalho da STN, cujos lançamentos deveriam ter sido feitos pelos órgãos setoriais. Vale ressaltar que o valor apresentado na Tabela 5, na ordem de 6,14 bilhões, foi determinado pelo grupo de trabalho, porém de acordo com o TCU há uma grande possibilidade do valor estar subavaliado.

O conjunto das omissões apontadas pelo TCU resultaram em uma queda do patrimônio líquido do BGU de aproximadamente 1,6\% em relação aos valores divulgados.

A Tabela 6, a seguir, apresenta o BP do exercício de 2015 publicado originalmente e o balanço adaptado com as informações encontradas pelo TCU. 
Tabela 6

BGU 2015 original e com a inclusão das informações off balance

\begin{tabular}{l|l|l|r}
\hline BGU 2015 - Original (em milhares) & (1.371.018.413,00 & Passivo circulante & $1.046 .070 .069,00$ \\
\hline Ativo circulante & $2.985 .633 .151,00$ & Passivo não circulante & $4.735 .108 .810,00$ \\
\hline Ativo não circulante & & Passivo total & $5.781 .178 .879,00$ \\
\hline & & Patrimônio Líquido & $-1.424 .527 .315,00$ \\
\hline & $4.356 .651 .564,00$ & Passivo e PL novo & $4.356 .651 .564,00$ \\
\hline Ativo total & & $1.046 .070 .069,00$ \\
\hline BGU 2015 - Incluindo as informações off balance (em milhares) & $1.046 .070 .069,00$ \\
\hline Ativo circulante & $1.371 .018 .413,00$ & Passivo circulante & $4.735 .108 .810,00$ \\
\hline Ativo circulante novo & $1.371 .018 .413,00$ & Passivo circulante novo & $17.740 .000,00$ \\
\hline Ativo não circulante & $2.985 .633 .151,00$ & Passivo não circulante & $6.140 .000,00$ \\
\hline & & Provisão passivos judiciais & $4.758 .988 .810,00$ \\
\hline & Passivos de etapas de cont. já exec. & $5.805 .058 .879,00$ \\
\hline Ativo não circulante novo & $2.985 .633 .151,00$ & Passivo não circulante novo & $-1.448 .407 .315,00$ \\
\hline & & Passivo total novo & $4.356 .651 .564,00$ \\
\hline
\end{tabular}

Fonte: resultados obtidos a partir dos dados pesquisados no TCU (2016) e no CGU (2016).

É perceptível, por meio desses achados, que os órgãos do Governo tiveram dificuldade para assimilar os novos métodos de reconhecimento dos fatos contábeis. Isso se torna mais claro na situação referente ao PAC, no qual esses entes ainda estão fortemente ligados à contabilidade orçamentária e não assimilaram a contabilidade patrimonial.

É importante ressaltar que este trabalho apenas se utilizou de achados quantificados, porém, nos relatórios do TCU há a sinalização de outras informações off balance que não foram quantificadas por várias razões, como o registro do passivo atuarial dos pensionistas e inativos militares. Outra ressalva é que das seis informações off balance do BGU encontradas nos três anos estudados, identificou-se apenas uma informação classificada como ativo, o que demonstra uma tendência em ter-se mais passivos off balance do que ativos off balance.

\section{CONSIDERAÇÕES FINAIS}

Este trabalho teve por objetivo apresentar evidências de informações off balance e seus impactos no Balanço Geral da União (BGU), a partir da análise categorial do Relatório e o Parecer Prévio sobre as Contas do Governo da República, elaborado pelo Tribunal de Contas da União, relativo ao período de 2013 a 2015, e dos relatórios de Prestação de Contas do presidente da República, elaborados pela Controladoria-Geral da União (CGU), relativos ao período de 2013 a 2015.

A revisão da literatura mostrou que as demonstrações contábeis são o núcleo da informação contábil, mesmo que a NBC T SP Estrutura Conceitual preveja que o alcance da informação contábil seja mais abrangente do que aquela evidenciada nas demonstrações contábeis. Outro ponto demonstrado é que o BGU contempla as informações orçamentárias, financeiras e contábeis dos entes e órgãos da Administração Pública Federal, em um determinado exercício financeiro.

Com relação às informações off balance, trata-se daquelas que não estão evidenciadas nas demonstrações contábeis, e que a manipulação da informação contábil não decorre somente da modificação artificial dos números contábeis, mas, também, da apresentação de certos aspectos econômicos e financeiros.

Os achados do estudo mostram que em 2013 a omissão de registros impactou negativamente o BGU na ordem de $158 \%$, saindo de uma situação superavitária no valor de mais de um trilhão de reais para uma situação deficitária de mais de 600 bilhões de reais, com 
destaque para a ausência de evidenciação contábil do passivo atuarial do regime próprio de previdência social.

Em 2014, as evidências de informações off balance encontradas no BGU não alteraram o patrimônio líquido do Governo Federal brasileiro de forma substancial como o ano de 2013, porém, caso fossem incluídas, as informações off balance identificadas em 2014 impactariam negativamente o PL em mais de 30\%, com destaque para a ausência de registro de passivos da União relativos a repasses de recursos de programas sociais, que ficou conhecido como "pedaladas fiscais", na ordem de 37,5 bilhões de reais.

O destaque do ano de 2015 foi a omissão do reconhecimento de provisão para passivos judiciais, de mais de 17 bilhões de reais, resultando em uma queda do patrimônio líquido do BGU de aproximadamente $1,6 \%$ em relação aos valores divulgados.

Uma questão a ser discutida é sobre a dificuldade dos órgãos federais em assimilar os novos métodos de reconhecimento dos fatos contábeis trazidos pelo processo de convergência da contabilidade pública brasileira aos padrões internacionais, como no caso do reconhecimento de provisões já anteriormente recomendadas pelo TCU. Também, as evidências mostram a tendência em se ter mais passivos off balance do que ativos off balance.

Para futuras pesquisas, recomenda-se analisar se as mudanças decorrentes da introdução da contabilidade patrimonial nas contas públicas estão contribuindo para que as informações contábeis do Governo Federal brasileiro passem a ser integralmente evidenciadas em suas demonstrações contábeis.

\section{REFERÊNCIAS}

Amaral, G. F., \& Lima, D. V. (2013). A contribuição da nova Contabilidade Pública sobre os efeitos dos ciclos políticos no Brasil. Revista de Ambiente Contábil, 5(2), 173-189.

Augustinho, S. M., \& Oliveira, A. G. (2014). A informação contábil pública como instrumento de controle social: a percepção de líderes comunitários da cidade de Curitiba. Revista de Informação Contábil, 8(2), 49-68.

Bardin, L. (1979). Análise de Conteúdo (L. A. Reto \& A. Pinheiro, Trad.). São Paulo: Edições 70, Livraria Martins Fontes.

Barros, A. J. P., \& Lehfeld, N. A. S. (2007). Fundamos de Metodologia Científica (3a ed.). São Paulo: Editora Pearson.

Benito, B., Montesinos, V., \& Bastida, F. (2008). An example of creative accounting in public sector: the private financing of infrastructures in Spain. Critical Perspectives on Accounting, (19), 963-986.

Constituição da República Federativa do Brasil. (1988). Recuperado em 30 abril, 2017, de http://www.planalto.gov.br/ccivil_03/constituicao/ConstituicaoCompilado.htm

Conselho Federal de Contabilidade. (2007). Orientações Estratégicas para a Contabilidade Aplicada ao Setor Público no Brasil. Recuperado em 10 março, 2017, de http://www3.tesouro.gov.br/contabilidade_governamental/downloads/CCASP_Orientacoes _Estrategicas_Contabilidade.pdf

Conselho Federal de Contabilidade. (2016). NBC TSP Estrutura Conceitual. Recuperado em 10 março, 2017, de http://www1.cfc.org.br/sisweb/SRE/docs/NBCTSPEC.doc 
Controladoria-Geral da União. (2015). Portaria n. 50.123, de 20 de novembro de 2015. Dispõe sobre as diretrizes para a elaboração da Prestação de Contas Anual do Presidente da República. Recuperado em 30 abril, 2017, de http://ramec.mec.gov.br/spo/2015orientacoes-tecnicas-da-setorial-contabil/encerramento-exercicio-2015/legislacao-1/4714portaria-cgu-n-50-123-de-20-11-2015-diretrizes-para-elaboracao-da-pcpr-2015-dou-23-112015/file

Controladoria-Geral da União. (2014). Prestação de Contas do Presidente da República: exercício 2013. Recuperado em 24 março, 2017, de http://www.cgu.gov.br/assuntos/auditoria-e-fiscalizacao/avaliacao-da-gestao-dosadministradores/prestacao-de-contas-do-presidente-da-republica/exercicios-anteriores/2013

Controladoria-Geral da União. (2015). Prestação de Contas do Presidente da República: exercício 2014. Recuperado em 24 março, 2017, de http://www.cgu.gov.br/assuntos/auditoria-e-fiscalizacao/avaliacao-da-gestao-dosadministradores/prestacao-de-contas-do-presidente-da-republica/exercicios-anteriores/2014

Controladoria-Geral da União. (2016). Prestação de Contas do Presidente da República: exercício 2015. Recuperado em 24 março, 2017, de http://www.cgu.gov.br/assuntos/auditoria-e-fiscalizacao/avaliacao-da-gestao-dosadministradores/prestacao-de-contas-do-presidente-da-republica/exercicios-anteriores/2015

Cruvinel, D. P., \& Lima, D. V. (2011). Adoção do regime de competência no setor público brasileiro sob a perspectiva das normas brasileiras e internacionais de contabilidade. Revista de Educação e Pesquisa em Contabilidade, 5(3), 69-85.

Dias, J. C. R., \& Vasconcelos, M. T. C. (2015). As características qualitativas da informação contábil no desenvolvimento do controle social: uma análise da percepção dos conselheiros municipais do Recife sobre a utilidade das informações contábeis. Revista Contabilidade Vista \& Revista, 26(2), 15-40.

Duarte, J. (org.). (2008). Métodos e Técnicas de Pesquisa em Comunicação (Cap. 17, pp. 267279). (2a ed.). São Paulo: Atlas.

Heald, D., \& Georgiou, G. (2011). The Substance of Accounting for Public-Private Partnerships. Financial Accountability \& Management, 27(2), 217-247.

International Federation of Accountants. (2010). Conceptual Framework for General Purpose Financial Reporting by Public Sector Entities: Elements and Recognition in Financial Statements. Consultation Paper. p. 68.

Iudícibus, S. (1997). Teoria da contabilidade. (5a ed.). São Paulo: Atlas.

Lewis, M. K. (2013). Off-balance sheet activities and financial innovation in banking. PSL Quarterly Review, 41(167).

Lima, D. V. (2016). Contabilidade da Dívida Pública. Brasília, Nov. 2016. 22 slides. Recuperado em 11 abril, 2017, de http://www.mpf.mp.br/atuacaotematica/ccr1/atuacao/eventos/jornadas-da-divida-publica/ii-jornada-de-debates-sobredivida-publica-1/IIJornadaDvidaPblicaDiana VazdeLima.ppt 
Lima, I. G., \& Carmo, C. R. S. (2014). Convergência das normas contábeis brasileiras às normas internacionais de contabilidade: um estudo sobre evidenciação adicional. Revista de Administração, 12(21), 37-54.

Milesi-Ferretti, G. M. (2004). Good, bad or ugly? On the effects of fiscal rules with creative accounting. Journal of Public Economics, 88(1-2), 377-394.

Padoveze, C. L. (2009) Sistemas de informações contábeis: fundamentos e análise. (6a ed.). São Paulo: Atlas.

Passos, L. H. S. (2012). O impacto das Normas Brasileiras de Contabilidade Aplicadas ao Setor Público: cenário atual e perspectivas na Administração Pública Federal. Revista de Administração de Roraima, 2(1), 110-135. Recuperado em 17 março, 2017, de http://revista.ufrr.br/index.php/adminrr/article/view/771

Paulo, E. (2007). Manipulação das informações contábeis: uma análise teórica e empírica sobre os modelos operacionais de detecção de gerenciamento de resultados. Tese de doutorado. Universidade de São Paulo, São Paulo, SP, Brasil.

Reis, C. E., Lima, D. V., \& Wilbert, M. D. (2015). Impacto do Registro Contábil da Provisão Matemática Previdenciária dos Servidores Públicos Federais no Balanço Geral da União. Anais do Congresso USP Controladoria e Contabilidade, São Paulo, SP, Brasil, 15.

Salgado, S. R., Wilbert, M. D., Lima, D. V., \& Oliveira, W. A. (2017). Concessão das rodovias federais brasileiras: evidências de ativos órfãos. Enfoque: Reflexão Contábil, 36(1), 105122.

Secretaria do Tesouro Nacional. (2012). Base de Preparação das Demonstrações e das Práticas Contábeis. BGU em Revista, 1(1). Recuperado em 18 março, 2017, de http://www.tesouro.fazenda.gov.br/documents/10180/243309/DCON+em+Revista+n\%C2 \%BA\%201.pdf/2aafc5a5-402b-47c7-86fc-fd844f0d1b99

Secretaria do Tesouro Nacional. (2015). Manual SIAFI: 020311 - Integração de saldos contábeis para elaboração do BGU. Recuperado em 22 março, 2017, de https://manualsiafi.tesouro.fazenda.gov.br

Secretaria do Tesouro Nacional. (2016). Manual SIAFI: 010400 - Glossário. Recuperado em 22 março, 2017, de https://manualsiafi.tesouro.fazenda.gov.br

Secretaria do Tesouro Nacional. (2017). Manual SIAFI: 020318 - Encerramento do Exercício. Recuperado em 22 março, 2017, de https://manualsiafi.tesouro.fazenda.gov.br

Secretaria do Tesouro Nacional. (2017). Manual de Contabilidade Aplicada ao Setor Público: Aplicado à União, Estados, Distrito Federal e Municípios. (7a ed.). Brasília: STN. Recuperado em 22 março, 2017, de http://tesouro.gov.br/mcasp

Silva, C. A. T., Gonçalves, R. S., Tavares, A. L., \& Lima, D. V. (2010). Influência do incentivo ao conservadorismo nas escolhas contábeis relacionadas ao reconhecimento de provisão de contingências passivas. Revista Universo Contábil, 6(4), 6-20. 
Tardoque, P. R. (2011). A qualidade da informação contábil na administração pública: uma proposta de melhoria da divulgação da informação, com enfoque nos atos de gestão. Dissertação de mestrado. Faculdade Escola de Comércio Álvares Penteado, São Paulo, SP, Brasil.

Tribunal de Contas da União. (2013). Relatório e Parecer Prévio sobre as contas do Governo da República: exercício de 2012. Brasília: TCU.

Tribunal de Contas da União. (2014). Relatório e Parecer Prévio sobre as contas do Governo da República: exercício de 2013. Brasília: TCU.

Tribunal de Contas da União. (2015). Relatório e Parecer Prévio sobre as contas do Governo da República: exercício de 2014. Brasília: TCU.

Tribunal de Contas da União. (2016). Relatório e Parecer Prévio sobre as contas do Governo da República: exercício de 2015. Brasília: TCU.

Villaverde, J., \& Fernandes, A. (2015). As 'pedaladas fiscais' do governo Dilma. Estadão. São Paulo. Recuperado em 7 abril, $2017, \quad$ de http://infograficos.estadao.com.br/economia/pedaladas-fiscais/index

Xavier, A. E., Jr., Paulo, E., Silva, J. D. G. da (2014). Estudo sobre a capacidade informacional das novas estruturas das demonstrações contábeis aplicadas ao setor público. ReCont, 5(1). Recuperado em $14 \quad$ março, $2017, \quad$ de http://www.seer.ufal.br/index.php/registrocontabil/article/view/1/pdf_12 